\title{
Herberto Helder: o Mundo como Gramática e Idioma
}

\author{
Silvana Maria Pessoa de Oliveira \\ Universidade Federal de Minas Gerais
}

\begin{abstract}
RESUMO: NESTE ENSAIO PRETENDE-SE DISCUTIR EM QUE MEDIDA A POÉTICA DE HERBERTO HELDER CONSTRÓI-SE NO INTERIOR DE UM DUPLO MOVIMENTO: DE UM LADO, A EXPOSIÇÃO DE UMA SUBJETIVIDADE FORTE E POR OUTRO, A TENDÊNCIA RADICAL QUE TEM O SUJEITO DE CONVERTER-SE EM OBJETO, DE TORNAR-SE COISA ATÉ A INDISTINÇÃO.
\end{abstract}

ABSTRACT: THIS ARTICLE INTENDS TO ANALYSE THE POETRY OF HERBERTO HELDER ACCOMPANYING THE DEVELOPMENT OF HIS WRITTEN ONES AND DETACHING HIS BASIC CHARACTERISTICS.

PALAVRAS-CHAVE: HERBERTO HELDER, POESIA PORTUGUESA CONTEMPORÂNEA, LITERATURA PORTUGUESA CONTEMPORÂNEA

KEY WORDS: CONTEMPORARY PORTUGUESE POETRY, HERBERTO HELDER, CONTEMPORARY PORTUGUESE LITERATURE 
ertas vertentes da poesia contemporânea evidenciam uma constante tendência do sujeito lírico a buscar converter-se em objeto, a pretender tornar-se coisa até praticamente a indistinção. É bem possível que essa propensão tenha se/plasmado no interior de uma conhecida "instabilidade multiforme das figurações autorais" (GUSMÃO, 1998) que ao longo da modernidade vem se firmando de maneira cada vez mais nítida e radical. Em conseqüência, o "afastamento do autor" pode ser visto tanto como "fato histórico" quanto como "condição do moderno" (GUSMÃO, 1998).

Em se tratando de Literatura Portuguesa, na sequência da obra paradigmática de Fernando Pessoa, diversos poetas, no decorrer do século XX, se empenharam em disseminar o processo de estranhamento e alterização posto em movimento pelo autor de "Tabacaria".

O poeta de que trata este texto, Herberto Helder, tem sua obra comumente associada à exposição de uma subjetividade lírica complexa e problemática, na qual estaria alicerçada parte significativa da poesia atualmente produzida em Portugal.

Para refletir sobre os processos de dessubjetivação na poesia portuguesa contemporânea e, em especial, na poesia de Herberto Helder, faz-se necessário recorrer aos fundamentos da lírica moderna em suas inúmeras configurações. Hugo Friedrich, autor de um dos mais notáveis livros sobre a lírica européia moderna, vê a despersonalização como o elemento constituinte da poesia moderna e em Charles Baudelaire o iniciador deste processo, por o poeta pretender abrigar-se em um eu que prescinde da encenação da expressão da vivência pessoal, individualista.

O crítico suíço entende a despersonalização como a exigência de que o poeta "não se entregue à embriaguez do coração", que ele não se perca no círculo "estreito" do eu, com suas emoções, sentimentos, sensações, enfim, seus estados de alma. A tarefa do poeta é a construção sistemática de uma arquitetura da língua, daí o ato poético ser concebido como produto de uma imaginação racionalizada, guiada pelo intelecto.

Por seu turno, Leyla Perrone-Moisés identifica no poeta de Flores do mal o pilar constituinte da modernidade. Nesta era, a poesia não pretende mais a primazia entre os discursos: assume-se como linguagem à parte, não comunicativa, hermética. Passando a "a ter um valor em si mesma, torna-se núcleo irradiador de sentidos infinitos, desafiando o leitor a dar prosseguimento ao ato criativo" (PERRONE-MOISÉS, 2000, p.27). 
Posteriormente, Arthur Rimbaud amplifica os procedimentos adotados por Baudelaire e assume a busca por uma "poesia desumanizada",que, não se dirigindo a um alguém em especial, monóloga, procurando atrair quem a escute. O poeta, criador de um novo lirismo que ganha força por ser anti-expressivo e despersonalizado, " parece conversar com uma voz para a qual não existe intérprete concebível, sobretudo lá, onde o Eu imaginado cedeu lugar a uma expressão sem o Eu" (FRIEDRICH, 1978, p.70). É também nesse sentido que em Rimbaud, o pensamento fala por si mesmo: “ Assisto ao desabrochar do meu pensamento, eu o vejo, eu o escuto (.....) É falso dizer: penso. Dever-se-ia dizer: pensa-se em mim". (RIMBAUD, citado por FRIEDRICH, 1978, p.62). Nessa perspectiva, o procedimento de "desumanização" teria como conseqüência a corrosão do triângulo autor-leitor-obra e operaria a separação entre obra e as outras duas referências "humanas". Trata-se de uma poesia que cria um "acontecimento sem eu", em que a linguagem não é mais comunicação, mas pura exteriorização de si mesma. Por sua vez, o sujeito é sempre um "ele", projetado num fora. No que concerne ao leitor, este não deve preocupar-se em decifrar o poema, pelo contrário, deve conviver com o enigmático, o obscuro e a partir daí construir sentidos para o poema.

Ao lado de Rimbaud, Stéphane Mallarmé opera o mais radical abandono da lírica baseada na vivência e na confissão e almeja alcançar o afastamento extremo daquilo que se pode denominar "vida natural". De acordo com esta perspectiva, a lírica moderna rege-se pela noção de exclusão: ela pressupõe o afastamento não só da pessoa particular, mas também da humanidade em geral. Particularmente o caminho percorrido por Mallarmé conduz do sujeito poético a uma neutralidade suprapessoal, a uma "desconcretização do real". Trata-se de uma idéia de lírica que pressupõe a elaboração precisa das palavras, a fim de que se tornem uma "voz que oculte tanto o poeta quanto o leitor" (citado por FRIEDRICH, 1978, p.111). Parece estar dado aqui o passo decisivo para o que posteriormente Roland Barthes denominará de "morte do autor".

A idéia de "desrealização" aparece em Mallarmé como conseqüência de uma insuficiência, entendida ontologicamente, entre realidade e linguagem. Ao poeta cabe buscar uma poesia em que a própria linguagem torne presente o Nada, já que este pode realizar-se mediante um suposto aniquilamento do real. Para esse poeta, a maior força da linguagem é a poesia. Por poesia entenda-se aquilo que é capaz de promover um aniquilamento do objeto concreto, completando 
este pensamento com o outro de que tal aniquilamento acontece porque o objeto deve tornar-se na palavra "idéia pura”, essência. Mas esta "idéia” não pode existir em lugar algum a não ser na palavra poética, que é obra de linguagem: o que nela acontece não pode ocorrer em nenhum mundo real.

É nesse sentido que a lírica de Mallarmé repele o leitor e se recusa a ser "humana". O poeta está só com sua linguagem. Sua poesia torna-se um dizer que tem evidência em si mesmo e assinala o privilégio maior da linguagem, que não é o de expressar um sentido, e sim o de criá-lo. À linguagem, é conferido um caráter impessoal, uma espécie de existência independente e absoluta. Ela não supõe ninguém que a expresse, ninguém que a ouça: "ela se fala e se escreve" (BLANCHOT, 1997, p. 47). Eis a condição de sua autoridade.

Se há algo que pode articular o pensamento de Mallarmé com o de Baudelaire e o de Rimbaud é o fato de organizarem-se em torno de uma cisão: aquela pressuposta entre a linguagem e a idealidade, entre o querer e o poder, entre a aspiração e a meta.

Contudo, a contribuição dada à poesia pelos chamados processos de "desumanização" reside no fato de que, naquela, o "homem" pode subsistir como linguagem criativa, inventiva. Pela via do poético, pode conceder a si mesmo um poder absoluto, ilimitado, já que "aniquila sua naturalidade própria, se exila do mundo, exila também este, para satisfazer sua liberdade própria” (FRIEDRICH, 1978, p.173).

\section{Herberto Helder: o mundo como gramática e idioma}

Em 1909, no "Manifesto Futurista”, Marinetti postula uma concepção do "humano" como algo absolutamente trivial, privado de importância ou significação transcendente: "O sofrimento de um homem não é para nós mais interessante que o sofrimento de uma lâmpada atingida pelo curto-circuito" (MARINET'TI citado por FRIEDRICH, 1978, p.171). Concebe-se a "desumanização" como algo que seria capaz de pôr em questão o humano, isto é, aquilo que seria próprio do homem. Inscrevendo-se na tradição de uma "poesia desumanizada", Herberto Helder é o arquiteto de uma poética que parte de um eu que pode vestir todas as máscaras, estender-se a todas as formas de existência, a todos os tempos, todos os povos. 
Às muitas variantes da desumanização pertence também uma lírica que enfatiza, de modo hiperbólico, as coisas. Os assuntos da poesia de Herberto Helder são, muitas vezes, flores, casas, pedras, astros, cometas. Estas coisas inscrevemse em uma atmosfera tão singular que é como se existissem em uma espécie de "irrealidade sobrenatural", para usar expressão de Hugo Friedrich. Nesse universo, o eu que os acolhe parece descarnado, mero suporte de linguagem.

Desdobrando-se, a noção de desumanização em Herberto Helder, comporta duas facetas bem distintas: a do anonimato e a da metamorfose. No poema que é o pórtico da obra de Herberto Helder, "Prefácio", há um "alguém" vagamente indicado por algumas ações: "alguém trouxera cavalos / alguém viera do mar / alguém lera livros, poemas, profecias, mandamentos, inspirações" (HELDER, 2004, p. 10). Desse alguém nada se sabe, nem mesmo se o alguém do primeiro verso e o do último verso são idênticos.

No poema VI, do livro Lugar, nenhum “eu” fala. Fala apenas a linguagem. Observe-se:

É a colina na colina, colina

Das colinas frias.

Colina devagar por ela acima, brotando

Sobre a raiz da colina. Oh fria raiz deitada

Na pedra sinistra fria da raiz

Da colina. Na húmida

Treva pedra vazia, na alegria

Abstracta dos fogos, das águas oh sombrias.

Colina profunda, colina de

Colina muda. Mexendo nos fogos,

Nas águas extremas vazias, nas massas

Nocturnas unas - respirando.

Batendo os leves pelos nas gotas frias

Das águas,

$\mathrm{E}$ as pesadas estrelas nas veias sombrias.

Colina acocorada na raiz ríspida

Da colina, feroz por ela abaixo, ladeada

Pelas paredes direitas da melancolia. Depois para cima, colina

Das colinas amargas estremes. 
De alegria para cima, na audácia das brutas

Assimetrias. Colina de pé

Sobre as visões, as culpas,

Os crimes - batendo os pés unidos na boca

Aberta das mães sinistras e vazias. Colina

$\mathrm{Na}$ colina nas colinas das ilusões

Quentes, duras, puras, sombrias. Colina

Em baixo e para cima.

E a colina em cima com árvores redondas,

Vivas, rápidas e oh frias.

Arvorezinhas da colina, vazias.

(Helder, 2004, p.177-178).

Por outro lado, a metamorfose, pensada como "combinatórias do heterogêneo" (LOPES, 2003, p.47) é um dos principais movimentos da poesia de Herberto Helder. Dramatiza-se, pela via do poético, uma tentativa de dar a ver, de tornar visível o processo de transformação das coisas, constituído por "brutas assimetrias". Esse é o modo pelo qual a sua poesia desrealiza-se, desumaniza-se. No poema acima, as coisas transfiguram-se, transfundem-se: a colina tem pelos, sente, possui uma natureza plural, nem inteiramente inorgânica, nem completamente orgânica.

Outro exemplo, agora de Cobra:

A força do medo verga a constelação do sexo.

Pelos canais nocturnos entra o mel, sai

$\mathrm{O}$ veneno branco.

O sono estrangula as chamas da cabeça nos veios atados.

As costas crepitam numa linha lunar

De clarabóias. Rutila

A flor do alimento, talhada: o ânus.

E brilha, rebrilha, uma luva puxada pelo avesso,

O corpo

Puxado pelo avesso

Com as estrelas desfechadas.

As casas ateiam-se.

(HELDER, 2004, p. 308) 
O espelho é uma chama cortada, um astro.

E há uma criança perpétua, por dentro, quando se vive em recintos

Cheios de ar alumiado. De fora, arremessam-se

Às janelas

As ressacas vivas dos parques. Ela toca o nó

Do espelho de onde salta

Uma braçada de luz. Cada lenço que ata,

A própria seda do lenço

O desata. E o rosto que jorra do espelho

Volta aos centros

Arteriais.

(HELDER, 2004, p.317)

A radicalização deste processo de despersonalização parece culminar na concepção do mundo como algo proveniente de uma natureza mista, assimétrica, sempre pronta a se transformar em outra coisa. Em Herberto Helder, a metamorfose é constituinte da natureza das coisas. Seu último livro publicado até então, Do mundo, dramatiza a gênese ou a cosmogonia de um universo cujo principal processo constitutivo são as misturas impuras, as assimetrias, as metamorfoses "monstruosas". Trata-se de um universo pensado como "somatória de massas de objetos ímpares", produto de uma matéria autônoma, pensante. Nesse sentido, é que se pode falar da "natureza entrançada" das coisas: o vegetal, o animal e o humano se misturam e se transformam, em um processo contínuo. Possui tal peculiaridade esse processo que se pode falar que Herberto Helder põe em movimento um "idioma da metamorfose", onde tudo é potência de outra coisa. Assim são " as constelações ao alto zoológicas arquejando, brutais/animais vivos" (HELDER, 2004, p.545) ou o "Ríspido, zoológico , / olho de constelação vendo o quê na rapina celeste?" (HELDER, 2004, p.532). As misturas assimétricas, sejam elas do orgânico com o inorgânico, do animal com o vegetal, do sideral com o botânico são um dos procedimentos recorrentes nesta poesia. Veja-se o poema:

Se se pudesse, se um inseto exímio pudesse,

Com o seu nome do princípio,

Entrar numa turquesa, monstruosa pela amplitude 
Da cor e do exemplo,

Se até ao coração da pedra e dele mesmo

Devorasse a matéria exaltada,

Por si e por ela e pelo nome primeiro ficaria

Vivo: profundamente

Num único nó de corpo,

E brilharia até se consumir

De si, todo - e a terra, suportaria

Ela o poema disso?

(HELDER, 2004, p. 552)

A fusão, culminância da metamorfose, é aqui concebida como um "único nó de corpo", figura que sintetiza o procedimento da metamorfose tal como pensada pela visão extraordinária, imanente de Herberto Helder. O último livro do poeta pode muito bem ser visto como o ponto alto de realização dessa poética que constrói e organiza misturas heteróclitas. É nesse sentido que se pode dizer que Herberto Helder cria, através da sua poesia, uma gramática do mundo e, no interior dessa gramática, constrói um idioma, uma propriedade particular, uma singularidade.

Visto sob outro ângulo, toda a poesia de Herberto Helder também pode ser pensada como um lento trabalho de escrita, no qual o mundo transmudase em oficina do poeta. Oficina rigorosa, que acaba por realizar outro tipo de metamorfose: a do poeta no poema, "a fusão dos dedos na matéria nascente" (HELDER, 2004, p. 540). Se, nessa oficina, o elemento que reúne as coisas é o desequilíbrio, a assimetria, a desordem "as coisas juntam-se/em desequilíbrio/ no grande buraco luminoso para cima” (HELDER, 2004, p. 558), é o próprio poema que as aglutina já que é, em Herberto Helder, matéria autônoma. Essa perspectiva autotélica do poema é corroborada pelos versos finais de Do mundo, nos quais o poeta acaba por ser devorado pelo poema. No interior desse mesmo movimento, que anuncia um "batismo primeiro e último", "o poema escreve o poeta nos recessos mais baixos" (HELDER, 2004, p. 561). Nesta poesia, importa que o poeta saia de cena para fazer brilhar o poema, o idioma ${ }^{1}$.

1 No caso de Herberto, essa idéia da autonomia do poema em relação ao poeta está exemplarmente desenvolvida em um artigo de Clara Riso no qual se pode ler: "O texto sai do organismo pela "língua / 
Silvina Rodrigues Lopes, uma das mais argutas e sensíveis leitoras-críticas de Herberto, assinala essa condição de apagamento da voz do autor, ao cunhar a expressão "escrita da mão esquerda, demoníaca", para se referir ao trabalho poético contido em Ou o poema contínuo. Graças a esta escrita, "aquele que escreve, canhestro" (LOPES, 2003, p. 19), perde qualquer identidade; a sua voz é a voz do poema e o seu nome o nome do poema. (...) Não há outro protagonista, porque o poeta que escreve é já, ou é apenas, o poema escrito, o qual, por conseguinte, é necessariamente biografia, escrita de uma vida na sua inacessibilidade"(LOPES, 2003, p. 19).

Por outro lado e conforme muito bem assinalou outro importante leitor da poesia de Herberto, o também poeta e crítico Joaquim Manuel de Magalhães, o comportamento da escrita de Herberto Helder pressupõe a entrada nos domínios da densidade reflexiva, filosófica e retórica da linguagem: "estamos, depois de ler um poeta assim, diante de um fato consumado: a poesia não necessita de teoria. Ela tem a capacidade intrínseca de pensar a si mesma" (MAGALHÃES, 1999, p. 144). Aproximar-se dessa linguagem, pensá-la pela via de seus dispositivos poéticos e acessá-la considerando-a na sua singularidade irredutível, eis a tarefa possível da leitura de poesia.

\section{Referências Bibliográficas}

BARRENTO, João. A palavra transversal - literatura e idéias no século XX. Lisboa: Cotovia, 1996.

BLANCHOT, Maurice. "O mito de Mallarmé". In: A parte do fogo. Trad. Ana Maria Scherer. Rio de Janeiro: Rocco, 1997.

COELHO, Eduardo Prado. "Herberto Helder: a não-separabilidade”. In: O cálculo das sombras. Porto: Asa, 1997. . “Como falar de Herberto Helder”. In: O cálculo das sombras. Porto: Asa, 1997. . "Questão de tacto”. In: O cálculo das sombras. Porto: Asa, 1997.

ou (por) outro órgão de amor" para dizer o que "o braço não podia" e, uma vez proferido, autonomizase para ir construir uma realidade. E é nessa realidade que passa a ter lugar o poeta, apenas depois de o poema actuar e só assim permitir que ele, poeta, exista, porque afinal só poderia haver poeta depois de haver poema, tal como a mãe, figura recorrente em Herberto, que só o é após o nascimento do filho" (RISO, http//www.eventos.uevora.pt), acessível em 21/02/2007. 
DAL FARRA, Maria Lúcia. A alquimia da linguagem: leitura da cosmogonia poética de Herberto Helder. Lisboa: IN/CM, 1986.

DÉCIO, João. Poesia e arte poética em Herberto Helder. Blumenau: EdiFURB, 2002.

DELEUZE, Gilles e GUATTARI, Felix. "Devir-intenso, devir-animal, devir-imperceptível”. In: Milplatôs - capitalismo e esquizofrenia. Vol. 4. Trad. Suely Rolnik. São Paulo: Editora 34, 1997.

DIOGO, Américo António Lindeza . Herberto Helder - texto, metáfora, metáfora do texto. Coimbra: Ângelus Novus, 2001.

FRIEDRICH, Hugo. Estrutura da lírica moderna. Trad. Marisa M. Curioni e Dora Ferreira da Silva. São Paulo: Duas Cidades, 1978.

GUIMARÃES, Fernando. A poesia contemporânea portuguesa e o fim da modernidade. Lisboa: Caminho, 1989.

GUSMÃO, Manuel. Anonimato ou alterização? Httpp://www.letras.puc-rio.br/catedra/revista/4 sem. 18html. Acessível em 17/12/2008.

HELDER, Herberto. Ou o poema contínuo. Lisboa: Assírio \& Alvim, 2004.

LOPES, Silvina Rodrigues. A inocência do devir - ensaio a partir da obra de Herberto Helder. Lisboa: Vendaval, 2003.

MAGALHÃES, Joaquim Manuel de. Rima pobre - poesia portuguesa de agora. Lisboa: Presença, 1999.

. Os dois crepúsculos - sobre poesia portuguesa actual e outras crônicas. Lisboa: A Regra do Jogo, 1981.

MARINHO, Maria de Fátima. Herberto Helder - a obra e o homem. Lisboa: Arcádia, 1982.

MARTELO, Rosa Maria. Em parte incerta - estudos da poesia portuguesa moderna e contemporânea. Porto: Campo das Letras, 2004.

PERRONE-MOISÉS, Leyla. “A inútil poesia de Mallarmé”. In: Inútil poesia. São Paulo: Companhia das Letras, 2000.

RISO, Clara. "Herberto Helder e Luiza Neto Jorge: movimentos alternados a duas mãos". Acessível em http://www.eventos.uevora.pt/comparada/volume1. (21/02/2007).

RUBIM, Gustavo. Arte de sublinhar. Coimbra: Angelus Novus, 2004.

SILVA, João Amadeu Oliveira Carvalho da. A poesia de Herberto Helder - Do contexto ao texto: uma palavra sagrada na noite do mundo. Lisboa: Fundação Calouste Gulbenkian, 2004.

SILVESTRE, Oswaldo Manuel e SERRA, Pedro. Século de ouro - antologia crítica da poesia portuguesa do século XX. Braga/Coimbra/Lisboa: Ângelus Novus/Cotovia, 2003. 